\title{
BMJ Open Impact of ethnicity on progress of glycaemic control in 131935 newly diagnosed patients with type 2 diabetes: a nationwide observational study from the Swedish National Diabetes Register
}

\author{
Araz Rawshani, ${ }^{1,2}$ Ann-Marie Svensson, ${ }^{1,2,3}$ Annika Rosengren, ${ }^{1,2}$ \\ Björn Zethelius, ${ }^{4,5}$ Björn Eliasson, ${ }^{1,2,3}$ Soffia Gudbjörnsdottir ${ }^{1,2,3}$
}

To cite: Rawshani A,

Svensson A-M, Rosengren A, et al. Impact of ethnicity on progress of glycaemic control in 131935 newly diagnosed patients with type 2 diabetes: a nationwide observational study from the Swedish National Diabetes Register. BMJ Open 2015;5:e007599. doi:10.1136/bmjopen-2015007599

- Prepublication history and additional material is available. To view please visit the journal (http://dx.doi.org/ 10.1136/bmjopen-2015007599).

Received 7 January 2015 Revised 31 March 2015 Accepted 22 April 2015

CrossMark

For numbered affiliations see end of article.

Correspondence to Dr Araz Rawshani; araz.rawshani@gu.se

\section{ABSTRACT}

Objectives: Studies on ethnic disparities in glycaemic control have been contradictory, and compromised by excessively broad categories of ethnicity and inadequate adjustment for socioeconomic differences. We aimed to study the effect of ethnicity on glycaemic control in a large cohort of patients with type 2 diabetes.

Setting: We used nationwide data (mainly from primary care) from the Swedish National Diabetes Register (2002-2011) to identify patients with newly diagnosed (within 12 months) type 2 diabetes.

Participants: We included 131935 patients (with 713495 appointments), representing 10 ethnic groups, who were followed up to 10 years.

\section{Primary and secondary outcome measures:}

Progress of glycated haemoglobin (HbA1c) for up to 10 years was examined. Mixed models were used to correlate ethnicity with $\mathrm{HbA1c}(\mathrm{mmol} / \mathrm{mol})$. The effect of glycaemic disparities was examined by assessing the risk of developing albuminuria. The impact of ethnicity was compared to that of income, education and physical activity.

Results: Immigrants, particularly those of nonWestern origin, received glucose-lowering therapy earlier, had 30\% more appointments but displayed poorer glycaemic control (2-5 mmol/mol higher $\mathrm{HbA1c}$ than native Swedes). Probability of therapy failure was $28-111 \%$ higher for non-Western groups than for native Swedes. High-income Western groups remained below the target-level of $\mathrm{HbA1c}$ for 4-5 years, whereas non-Western populations never reached the target level. These disparities translated into $51-92 \%$ higher risk of developing albuminuria. The impact of ethnicity was greater than the effect of income and education, and equal to the effect of physical activity.

Conclusions: Despite earlier pharmacological treatment and more frequent appointments, immigrants of non-Western origin display poorer glycaemic control and this is mirrored in a higher risk of developing albuminuria.
Strengths and limitations of this study

- To our knowledge, this is the largest study on ethnic differences in progress of glycaemic control. We included 131935 patients (with 713495 appointments) who were followed up to 10 years.

- All major ethnic groups in the world were represented in this study cohort and they had fully equal access to, and use of, healthcare, regardless of ethnic and socioeconomic background. Indeed, we report that immigrants had higher consumption of healthcare. This contrasts against previous studies, which have been hampered by inappropriately broad categories of ethnicity, cross-sectional design, small samples, short follow-up and unequal access to or consumption of healthcare.

- The longitudinal design, with at least annually updated information on all time-varying variables, allows for reliable estimates of the effect of ethnicity. We could control adequately for socioeconomic, demographic and health-related confounders.

- The main findings (immigrants, particularly those of non-Western origin, display poor glycaemic control and have a considerably higher risk of developing albuminuria) indicate that much can be done to improve diabetes care for a large proportion of the diabetic population in Western countries.

- When extrapolating our results, the fact that these ethnic differences could be expected in an equitable healthcare system needs to be taken into account. This should be taken into consideration in countries where access to healthcare is not equitable.

\section{INTRODUCTION}

Tight glucose control in type 2 diabetes has shown long-term beneficial effects on microvascular complications, cardiovascular 
disease and mortality. ${ }^{1-5}$ Studies of ethnic disparities in glycaemic control have been contradictory. ${ }^{6-9}$ They have, however, been hampered by inappropriately broad categories of ethnicity, cross-sectional design, small samples, short follow-up and unequal access to-or consumption of-healthcare. There are no reliable estimates of the true effect of ethnicity on glycaemic control.

This issue is important in Western societies, which are becoming more ethnically diverse due to accelerated migration from other areas of the world. ${ }^{10}$ The ethnic admixture of Western societies is currently far more diverse than the risk estimate tools of clinicians are prepared to handle. Immigrants may be at particular risk due to genetic susceptibility to insulin resistance, ${ }^{11} 12$ difficult transitional phases, and rapid changes in diet and lifestyle, ${ }^{13}$ as well as linguistic, cultural and financial barriers to obtaining proper healthcare. ${ }^{14} 15$

Sweden is an ethnically heterogeneous country in which all inhabitants enjoy access to every level of healthcare at a minimal cost. ${ }^{16}$ Immigrants are targeted in an effort to promote healthy lifestyles and consumption of healthcare. ${ }^{1718}$ The great majority of Swedes with type 2 diabetes are included in the Swedish National Diabetes Register, which we used to analyse the impact of ethnicity on the progress of glycaemic control and on albuminuria as a marker for diabetic complications.

\section{METHODS}

\section{Data sources}

Swedish authorities manage several nationwide registers, which may be linked through the unique personal identification number assigned to every Swede. The National Diabetes Register (NDR) has been described previously. ${ }^{19}$ It was launched in 1996 as a caregiver tool for local quality assurance purposes and as a feed-back tool in diabetes care. ${ }^{20}$ Data provided by nurses and physicians trained in register procedures, are obtained at visits to outpatient clinics of hospitals and primary care clinics. Clinical information and various measurements are updated at least once a year.

Patients with at least one entry in the NDR from 1 January 2002 to 31 December 2011 were included if they had been reported within 12 months of the date of diagnosis. Ninety-six per cent of the subjects had been diagnosed with type 2 diabetes on the basis of a clinical assessment. The remainder were included on the basis of the following definition: age 40 or older at the time of diagnosis and treated either with diet only, diet combined with oral hypoglycaemic agents (OHA), or a combination of OHA combined and insulin. This definition has been validated and used previously. ${ }^{21-23}$

\section{Measures}

Data on annual income in Swedish kronor, highest educational level regardless of country of domicile and country of birth (used as proxy for ethnicity/race), were obtained from the Longitudinal Integration Database for Health Insurance and Labour Market Studies, which is an official database administered by the Swedish National Board of Health and Welfare. Educational level was stratified into lower (9 years or less-the length of compulsory education in Sweden), intermediate (1012 years-upper secondary) and higher (college or university). Income was stratified into quintiles (Q1 to Q5), with the highest (Q5) being the reference. Ethnic categories were based on an appraisal of ancestry and geography, ${ }^{24}$ with the exception of the fact that Nordic countries were classified separately in the present study for the purpose of examining whether immigrants from neighbouring countries also exhibited differences. Native Swedish patients served as the reference group. Sixty-two individuals were excluded because information about their country of birth was unavailable.

Glycaemic control was measured as HbA1c. Analyses were quality-assured nationwide by regular calibration with the HPLC Mono-S method, and then converted to mmol/ mol (International Federation of Clinical Chemistry (IFCC) ). ${ }^{25}$ Microalbuminuria was defined as two positive results for three urine samples obtained within 1 year, with positivity defined as an albumin:creatinine ratio of 3 to $30 \mathrm{mg} / \mathrm{mmol}$ (approximately $30-300 \mathrm{mg} / \mathrm{g}$ ) or a urinary albumin clearance of $20-200 \mu \mathrm{g} / \mathrm{min} \quad(20-300 \mathrm{mg} / \mathrm{L})$. Macroalbuminuria was defined as an albumin:creatinine ratio of more than $30 \mathrm{mg} / \mathrm{mmol}$ (close to 300 or more $\mathrm{mg} / \mathrm{g}$ ) or a urinary albumin clearance of more than $200 \mu \mathrm{g} / \mathrm{min}(>300 \mathrm{mg} / \mathrm{L})$. Body mass index (BMI) was calculated as weight in kilograms divided by height in metres squared. Systolic blood pressure was the mean value of two supine readings (Korotkoff 1-5) with a cuff of appropriate size and after at least $5 \mathrm{~min}$ of rest. Low-density lipoprotein, high-density lipoprotein and total cholesterol were measured in $\mathrm{mmol} / \mathrm{L}$. Physical activity was rated from 1 (never) to 5 (daily). Smoking was coded as present if the patient currently smoked. Use of lipid lowering medications was dichotomised. Glucose-lowering treatment was categorised as diet and lifestyle modifications, oral hypoglycaemic agents (OHAs), insulin or insulin and OHAs. Antihypertensive medication was dichotomised. Estimatedglomerular filtration rate (eGFR) was calculated by the Modification of Diet in Renal Disease equation. ${ }^{26}$ A history of cardiovascular disease (CVD) was defined as previous hospitalisation due to acute myocardial infarction or stroke (International Classification of Diseases (ICD)-10, I21, I60-I69; ICD-9, 410, 430-434, 436-438) according to the Swedish National Discharge Register, which is a reliable and validated method. ${ }^{27}$ All time-varying variables are updated in the NDR following each appointment.

\section{Analyses and statistics \\ Baseline}

The first observation was used to present characteristics at time of diagnosis (within 12 months). Continuous variables are reported as means, percentages and quintiles. $\mathrm{T}$ tests were used for continuous variables with native Swedes as the reference group. $\chi^{2}$ Tests were used 
for categorical variables. A $p$ value $<0.01$ was considered statistically significant but multiple testing should be considered when interpreting the results.

\section{Glycaemic control}

Progress of glycaemic control was calculated as an unadjusted annual mean in relation to ethnicity. Adjusted figures were calculated using linear regression, to estimate differences in $\mathrm{mmol} / \mathrm{mol}$. Logistic regression was used to estimate the probability of achieving glycaemic control (ie, reaching target-level HbAlc $<52 \mathrm{mmol} / \mathrm{mol}$ ) during the second year after diagnosis.

To examine whether hypothesised differences in glycaemia are reflected on the risk of complications, we calculated the probability of developing albuminuria during the second year after diagnosis.

Mixed-effect models were used to account for repeated measurements on the same unit. ${ }^{29-31}$ HbAlc was centred around the mean.

Kaplan-Meier calculations were used to examine whether time to pharmacological treatment differed among ethnic groups. This was carried out to examine whether differences in HbAlc could be explained by disparities in use of medications.

Analyses were performed with SAS V.9.4 (SAS Institute, USA) and R (R Foundation for Statistical Computing).

\section{RESULTS}

We included 131935 individuals with newly diagnosed type 2 diabetes. A total of 713495 appointments were registered. All major ethnic groups were represented in the study (see online supplementary figure A). A total of $82.7 \%$ of the study population consisted of native Swedes. Immigrants had more appointments per year. Non-Western immigrants in particular had almost 30\% more appointments (table 1$)$.

\section{Characteristics at the time of diagnosis}

Table 1 presents characteristics at the time of diagnosis. The proportion of males varied from $37 \%$ (East Asia) to $70 \%$ (Mediterranean Basin). Patients from high-income Western countries were as much as 18 years older at the time of diagnosis. Particularly low age at the time of diagnosis was found for South Asia (46), East Asia (50) and Sub-Saharan Africa (47.3). BMI was $2-3 \mathrm{~kg} / \mathrm{m}^{2}$ lower among non-Western groups. Native Swedish patients had the lowest mean HbAlc $(51.9 \mathrm{mmol} / \mathrm{mol})$ of all groups. Low-income and non-Western groups had HbAlc ranging from 54 to $58 \mathrm{mmol} / \mathrm{mol}$. Systolic blood pressure was lower among non-Western groups. Lipid profiles were less favourable among non-Western groups. There were no major ethnic differences in terms of physical activity. Smoking rates were higher among patients from the Middle East, North Africa and lowincome Europe. A history of CVD was more common among Western groups, but non-Western groups were 10-12 years younger at the onset of CVD. The overall prevalence of albuminuria was approximately $14 \%$, and there were no noteworthy ethnic differences. College or university education was more common among non-Western populations, but they were generally in lower income quintiles.

\section{GLYCAEMIC CONTROL-CRUDE FIGURES}

HbA1c declined during the first 1-3 years of follow-up and then increased for all ethnic groups (figure 1). However, there were conspicuous and consistent ethnic differences in HbAlc levels throughout the study. Swedish patients (the reference category) had the lowest mean HbAlc at every point in time while patients from high-income Western countries had only slightly higher levels. Patients from low-income European countries, Russia and Central Asia, as well as all non-Western populations, had substantially higher HbAlc levels throughout the study. On average, Swedish and other Nordic populations remained below the target level until the fifth year. Mediterranean Basin, high-income European countries, North American and Oceanic populations, remained below the target level until the fourth year, whereas low-income European countries, Russian and Central Asian populations remained below only until the second year. The remaining five ethnic groups did not reach the target level at any point.

\section{GLYCAEMIC CONTROL-ADJUSTED FIGURES}

Since there was an interaction $(p<0.0001)$ between ethnicity and glucose-lowering treatment, we stratified the analysis by type of treatment. Table 2 presents $\beta$ coefficients (ie, predicted difference in $\mathrm{mmol} / \mathrm{mol} \mathrm{HbAlc}$ ) by ethnicity. To convey a sense of the impact of ethnicity as compared to other factors, coefficients for physical activity are also presented.

Being from Sub-Saharan Africa, South Asia, East Asia, the Middle East and North Africa, Latin America or lowincome European countries, Russia and Central Asia predicted substantially higher HbA1c. East Asian ethnicity predicted $1.8-3.8 \mathrm{mmol} / \mathrm{mol}$ higher HbAlc, depending on the stratum. Similarly, low-income European countries, Russia and Central Asia predicted $1.2-1.9 \mathrm{mmol} / \mathrm{mol}$ higher HbAlc. Latin America and the Caribbean predicted $1.9-4.8 \mathrm{mmol} / \mathrm{mol}$ higher HbAlc. South Asian origin predicted 1.9-4.2 mmol/mol higher HbAlc. Sub-Saharan Africa predicted 1.6$3.6 \mathrm{mmol} / \mathrm{mol}$ higher HbAlc. In comparison, no physical activity predicted $0.8-1.3 \mathrm{mmol} / \mathrm{mol}$ higher HbAlc, as compared to daily physical activity.

\section{PROBABILITY OF FAILURE TO ACHIEVE THE TARGET LEVEL DURING THE SECOND YEAR}

Low-income European countries, Middle East and North Africa, East Asia, Sub-Saharan Africa and South Asia displayed substantially higher odds of not achieving the target-level for HbA1c (figure 2). ORs (95\% CI) for East 
Table 1 Characteristics of 131935 individuals with newly diagnosed type 2 diabetes by ethnicity/race

\begin{tabular}{|c|c|c|c|c|c|c|c|c|c|c|c|}
\hline & All & Sweden & $\begin{array}{l}\text { Nordic } \\
\text { countries }\end{array}$ & $\begin{array}{l}\text { Europe (high } \\
\text { income), North } \\
\text { America and } \\
\text { Oceania }\end{array}$ & $\begin{array}{l}\text { Mediterranean } \\
\text { Basin }\end{array}$ & $\begin{array}{l}\text { Europe (low } \\
\text { income), Russia } \\
\text { and Central Asia }\end{array}$ & $\begin{array}{l}\text { Middle East and } \\
\text { North Africa }\end{array}$ & $\begin{array}{l}\text { Sub-Saharan } \\
\text { Africa }\end{array}$ & South Asia & East Asia & $\begin{array}{l}\text { Latin America } \\
\text { and Caribbean }\end{array}$ \\
\hline$n(\%)$ & 131935 & $\begin{array}{l}109058 \\
(82.66)\end{array}$ & $6760(5.12)$ & $3306(2.51)$ & $511(0.39)$ & $3870(2.93)$ & $5031(3.81)$ & $1127(0.85)$ & $610(0.46)$ & $802(0.61)$ & $860(0.65)$ \\
\hline Males & $57(75083)$ & $57(62526)$ & $51(3479)$ & $53(1751)$ & $70(360)$ & $54(2075)$ & 62 (3142) & $59(663)^{*}$ & $56(344)^{\star}$ & $37(298)$ & $52(445)$ \\
\hline Age (years) & $62.8(12.5)$ & $63.7(12.2)$ & $63.8(10.5)^{\star}$ & $64.4(11.8)$ & $62.5(10.6)^{\star}$ & $57.6(11.7)$ & $52.3(11.2)$ & $47.3(11.2)$ & $46.0(11.3)$ & $50.0(12.8)$ & $54.5(12.0)$ \\
\hline Annual visits & $1.73(2.14)$ & $1.67(2.0)$ & $1.80(2.22)$ & $1.96(2.70)$ & $2.20(3.24)$ & $2.05(2.70)$ & $2.30(3.34)$ & $2.22(3.42)$ & $2.32(3.40)$ & $1.91(2.70)$ & $2.50(3.20)$ \\
\hline BMI $\left(\mathrm{kg} / \mathrm{m}^{2}\right)$ & $30.4(5.5)$ & $30.3(5.5)$ & $31.2(5.6)$ & 30.5 (5.3) & $30.1(4.8)^{\star}$ & $31.3(5.3)$ & $30.9(5.2)$ & $28.8(5.4)$ & $28.6(5.2)$ & $27.3(4.3)$ & $31.4(5.5)$ \\
\hline $\begin{array}{l}\text { Waist circumference } \\
(\mathrm{cm})\end{array}$ & $104.7(13.4)$ & $105.2(13.5)$ & $106.3(13.5)$ & $104.2(12.9)$ & $104.4(11.8)$ & $105.0(11.9)$ & $103.6(11.5)$ & $100.2(11.4)$ & $97.8(11.8)$ & $92.4(11.2)$ & $104.3(11.7)$ \\
\hline $\mathrm{HbA} 1 \mathrm{c}(\mathrm{mmol} / \mathrm{mol})$ & $52.2(15.4)$ & $51.9(15.1)$ & $52.3(15.2)^{\star}$ & $52.2(14.7)^{\star}$ & $52.8(15.2)^{*}$ & $54.3(16.8)$ & $54.9(17.2)$ & $58.0(19.8)$ & $55.8(16.7)$ & $55.9(17.1)$ & $56.7(19.8)$ \\
\hline Systolic BP (mm Hg) & $137.5(17.2)$ & $138.1(17.1)$ & $139.5(17.4)$ & $138.2(17.4)^{\star}$ & $134.1(16.2)$ & $135.2(18.2)$ & $129.3(16.4)$ & $126.9(16.4)$ & $124.8(14.4)$ & $126.7(15.9)$ & $130.8(15.4)$ \\
\hline Chol/HDL ratio & $4.5(1.5)$ & $4.4(1.5)$ & $4.3(1.5)$ & $4.5(1.6)^{\star}$ & $4.6(1.4)^{\star}$ & $4.9(1.7)$ & $4.8(1.5)$ & $4.6(1.5)$ & $4.8(1.4)$ & $4.4(1.3)^{\star}$ & $4.7(1.5)$ \\
\hline LDL/HDL ratio & $2.6(1.1)$ & $2.6(1.1)$ & $2.5(1.1)$ & $2.6(1.1)^{\star}$ & $2.8(1.1)$ & $2.9(1.2)$ & $2.9(1.1)$ & $2.9(1.1)$ & $2.9(1.0)$ & $2.6(1.0)^{*}$ & $2.7(1.1)$ \\
\hline eGFR (mL/min) & $83.4(25.2)$ & $81.8(24.0)$ & $83.0(22.3)$ & $81.2(21.8)^{*}$ & $87.2(25.0)$ & $90.4(37.4)$ & $99.9(24.9)$ & $124.9(39.1)$ & $100.0(23.9)$ & $100.9(28.0)$ & $96.2(26.6)$ \\
\hline Smoker & 15 (19 657) & $14(15$ 173) & $20(1341)$ & $17(556)^{\star}$ & 19 (99) & $23(888)$ & 22 (1098) & $13(149)^{\star}$ & $13(77)^{*}$ & $15(122)^{\star}$ & $18(154)$ \\
\hline No physical activity & 12 (15 973) & $12(12935)$ & $13(907)^{*}$ & $12(390)^{*}$ & $15(76)^{*}$ & $13(497)^{*}$ & $16(803)$ & $11(128)^{*}$ & $13(82)^{*}$ & $8(66)$ & $10(89)^{*}$ \\
\hline $\begin{array}{l}\text { Daily physical activity } \\
\text { Income and education }\end{array}$ & $26(33983)$ & $26(28207)$ & $24(1651)^{\star}$ & $25(842)^{\star}$ & $27(139)^{\star}$ & $31(1186)^{*}$ & $22(1116)$ & $23(260)^{*}$ & $23(142)^{*}$ & $29(233)^{\star}$ & $24(207)^{\star}$ \\
\hline Income Q1 (lowest) & 20 (24 925) & $16(16872)$ & 23 (1439) & $27(852)$ & $23(113)$ & 41 (1538) & 55 (2745) & $47(526)$ & $35(212)$ & $42(333)$ & 35 (295) \\
\hline Income Q5 (highest) & 20 (24 928) & $22(22068)$ & 15 (928) & $14(452)$ & $14(69)$ & 11 (398) & $10(485)$ & $15(165)$ & $17(101)$ & $14(113)$ & $18(149)$ \\
\hline$<9$ years education & $39(51890)$ & $40(43495)$ & 44 (3005) & $25(814)$ & $41(211)$ & $35(1366)^{\star}$ & 37 (1883) & $33(376)$ & $24(148)$ & $42(335)^{*}$ & $30(257)$ \\
\hline $\begin{array}{l}10-12 \text { years } \\
\text { education }\end{array}$ & $43(56$ 146) & $43(47370)$ & $40(2734)^{\star}$ & 48 (1593) & $42(216)$ & $39(1516)^{*}$ & $29(1444)$ & 35 (399) & $44(267)^{*}$ & $30(243)$ & $42(364)^{*}$ \\
\hline $\begin{array}{l}\text { University/college } \\
\text { education }\end{array}$ & $17(22$ 140) & $16(17811)$ & $12(790)$ & $24(793)$ & $13(68)$ & $15(576)^{*}$ & 25 (1275) & $22(243)$ & $29(176)$ & $24(193)$ & $25(215)$ \\
\hline \multicolumn{12}{|c|}{ Glucose-lowering treatment } \\
\hline Diet & $53(70445)$ & $54(59371)$ & $53(3602)$ & $53(1763)^{*}$ & $49(251)^{\star}$ & $48(1854)^{\star}$ & 44 (2225) & $38(429)$ & $42(255)$ & $40(320)$ & $44(375)$ \\
\hline $\mathrm{OHA}$ & 37 (49 261) & 36 (39 662) & $38(2599)^{*}$ & $38(1240)^{*}$ & $43(219)$ & $43(1653)$ & 47 (2352) & $48(537)$ & $47(288)$ & $45(364)$ & $40(347)$ * \\
\hline Insulin & $5(6199)$ & 5 (5249) & $4(251)^{*}$ & $4(148)^{*}$ & $4(21)^{*}$ & $4(143)^{*}$ & $3(164)$ & $7(84)$ & $5(30)^{*}$ & $7(59)$ & $6(50)^{*}$ \\
\hline $\begin{array}{l}\text { Insulin+OHA } \\
\text { Complications }\end{array}$ & $4(5457)$ & $4(4318)$ & $4(284)$ & $4(136)^{*}$ & $4(18)^{\star}$ & $5(202)^{*}$ & $5(260)$ & $6(69)$ & $6(35)^{\star}$ & $7(55)$ & $9(80)$ \\
\hline Albuminuria & $14(17988)$ & $14(14845)$ & $14(920)^{*}$ & $14(453)^{*}$ & $17(88)^{*}$ & $13(502)^{*}$ & $14(701)^{\star}$ & $14(157)^{*}$ & $12(75)^{\star}$ & $13(106)^{*}$ & $16(141)$ \\
\hline Previous CVD & $20(26166)$ & $21(22373)$ & $23(1555)$ & $23(759)$ & $19(98)^{*}$ & $16(610)^{*}$ & $11(547)$ & $4(46)$ & $8(47)$ & $6(48)$ & $10(83)$ \\
\hline
\end{tabular}

Sweden is the reference group for ethnicity.

${ }^{*}$ No statistically significant difference at the 0.01 level.

BMI, body mass index; BP, blood pressure; CVD, cardiovascular disease; HbA1c, glycated haemoglobin; OHA, oral hypoglycaemic agents; eGFR, estimated-glomerular filtration rate; LDL, low-density lipoprotein; HDL,

high-density lipoprotein. 


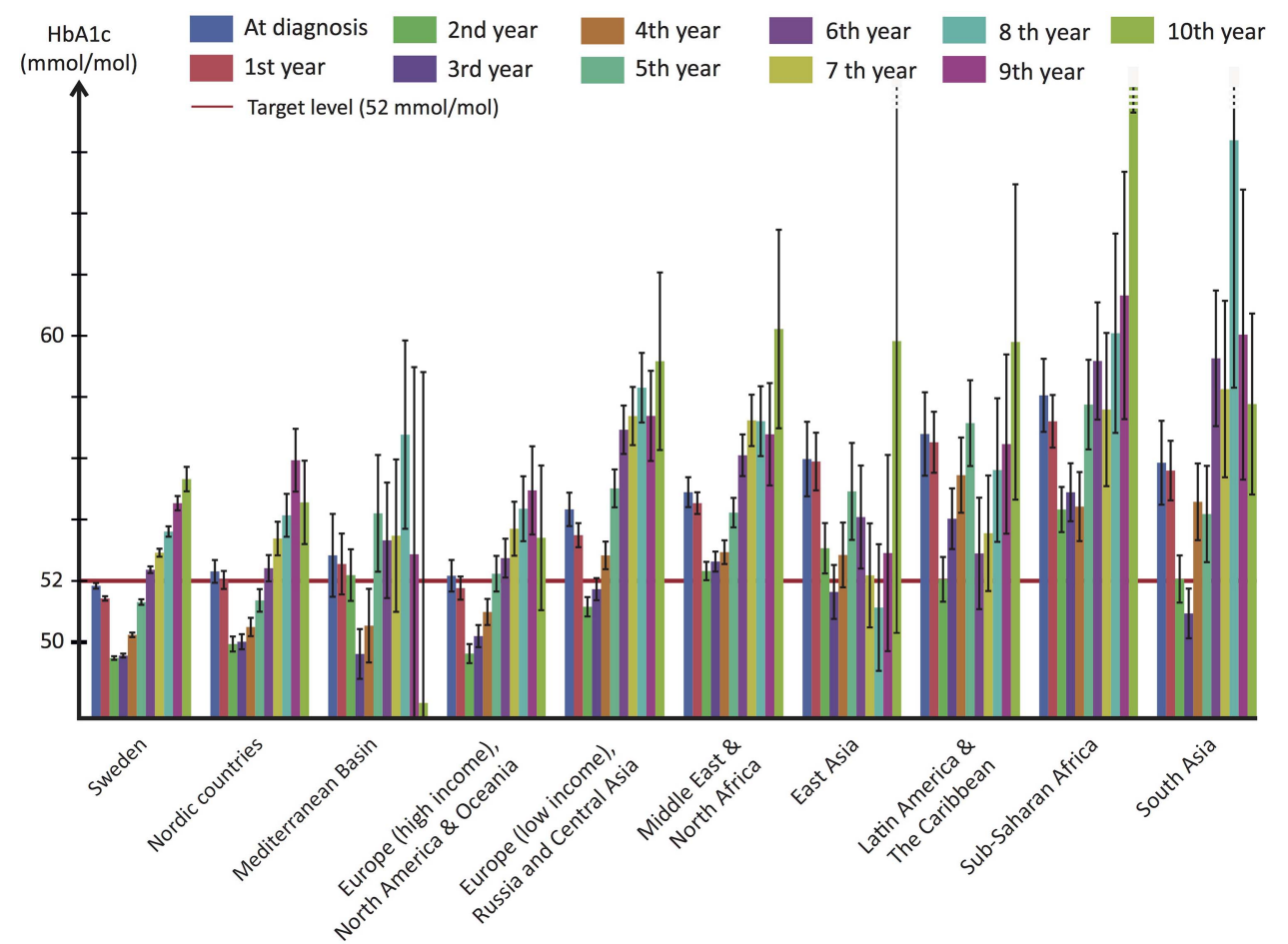

Figure 1 Progress of glycaemic control from time of diagnosis by ethnicity/race. Annual mean glycated haemoglobin from time of diagnosis by ethnicity/race. The red horizontal line in the background depicts the national target level $(52 \mathrm{mmol} / \mathrm{mol})$ set for type 2 diabetes.

Asia, Sub-Saharan Africa and South Asia were 1.76 (1.22, $2.54), 1.78(1.29,2.45)$ and $2.11(1.35,3.29)$, respectively. The effects of income and education were significant, although less pronounced. Not being physically active was associated with $57 \%$ higher odds of failure, as compared to daily physical activity.

\begin{tabular}{|c|c|c|c|}
\hline & Diet and lifestyle & OHA & Insulin ( $\pm \mathrm{OHA})$ \\
\hline \multicolumn{4}{|l|}{ Ethnicity/race } \\
\hline Sweden & Reference & Reference & Reference \\
\hline East Asia & 3.79 (2.59 to 5$)$ & $1.84(0.7$ to 2.97$)$ & $2.13(-0.36$ to 4.62$)$ \\
\hline Europe (high-income), North America and Oceania & $0.14(-0.37$ to 0.65$)$ & $0.19(-0.41$ to 0.79$)$ & $1.86(0.42$ to 3.3$)$ \\
\hline Europe (low-income), Russia and Central Asia & $1.58(1.05$ to 2.11$)$ & $1.2(0.66$ to 1.74$)$ & $1.89(0.63$ to 3.16$)$ \\
\hline Latin America and The Caribbean & 1.89 (0.76 to 3.02$)$ & $2.42(1.3$ to 3.54$)$ & 4.84 (2.6 to 7.07$)$ \\
\hline Mediterranean Basin & $0.57(-0.74$ to 1.88$)$ & $0.61(-0.84$ to 2.05$)$ & $1.17(-2.7$ to 5.04$)$ \\
\hline Middle East and North Africa & 1.85 (1.37 to 2.34$)$ & $0.93(0.46$ to 1.41$)$ & 2.79 (1.58 to 4.01$)$ \\
\hline Nordic countries & $-0.01(-0.36$ to 0.35$)$ & $0.19(-0.22$ to 0.6$)$ & $0.81(-0.19$ to 1.8$)$ \\
\hline South Asia & 4.21 (2.85 to 5.56$)$ & $1.93(0.6$ to 3.25$)$ & $1.91(-1.12$ to 4.94$)$ \\
\hline Sub-Saharan Africa & $3.26(2.22$ to 4.3$)$ & 3.61 (2.57 to 4.64$)$ & $1.58(-0.47$ to 3.63$)$ \\
\hline \multicolumn{4}{|l|}{ Physical activity } \\
\hline Daily physical activity & Reference & Reference & Reference \\
\hline 3-5 times/week & $0.07(0.01$ to 0.14$)$ & $0.11(0.01$ to 0.22$)$ & $0.19(-0.06$ to 0.45$)$ \\
\hline 1-2 times/week & $0.26(0.19$ to 0.34$)$ & 0.51 (0.4 to 0.62$)$ & $0.74(0.46$ to 1.01$)$ \\
\hline Less than once/week & $0.48(0.39$ to 0.57$)$ & $1.03(0.9$ to 1.17$)$ & $1.38(1.06$ to 1.7$)$ \\
\hline No physical activity & 0.76 (0.66 to 0.86$)$ & $1.20(1.06$ to 1.35$)$ & $1.32(1.00$ to 1.65$)$ \\
\hline
\end{tabular}

Figures are $\beta$ coefficients $(95 \% \mathrm{Cl})$ that predict the change in $\mathrm{HbA1c}(\mathrm{mmol} / \mathrm{mol})$.

The effect of physical activity is presented for comparison.

Example of interpretation: after accounting for included covariates, East Asian ethnicity predicts $3.79 \mathrm{mmol} / \mathrm{mol}$ higher $\mathrm{HbA} 1 \mathrm{c}$ among persons on diet and lifestyle modifications.

Model adjustments: age, sex, age at onset of diabetes, duration of diabetes, quadratic effect of duration of diabetes, BMI, smoking status, history of cardiovascular disease, physical activity, income, education, lipid lowering medication and eGFR.

$\mathrm{BMI}$, body mass index; eGFR, estimated-glomerular filtration rate; HbA1c, glycated haemoglobin; OHA, oral hypoglycaemic agents. 
Figure 2 Probability (OR) of achieving glycaemic control (<52 $\mathrm{mmol} / \mathrm{mol}$ ) during the second year after diagnosis. Adjusted for ethnicity, sex, age, body mass index, income, education, smoking status, physical activity and type of glucose-lowering treatment.

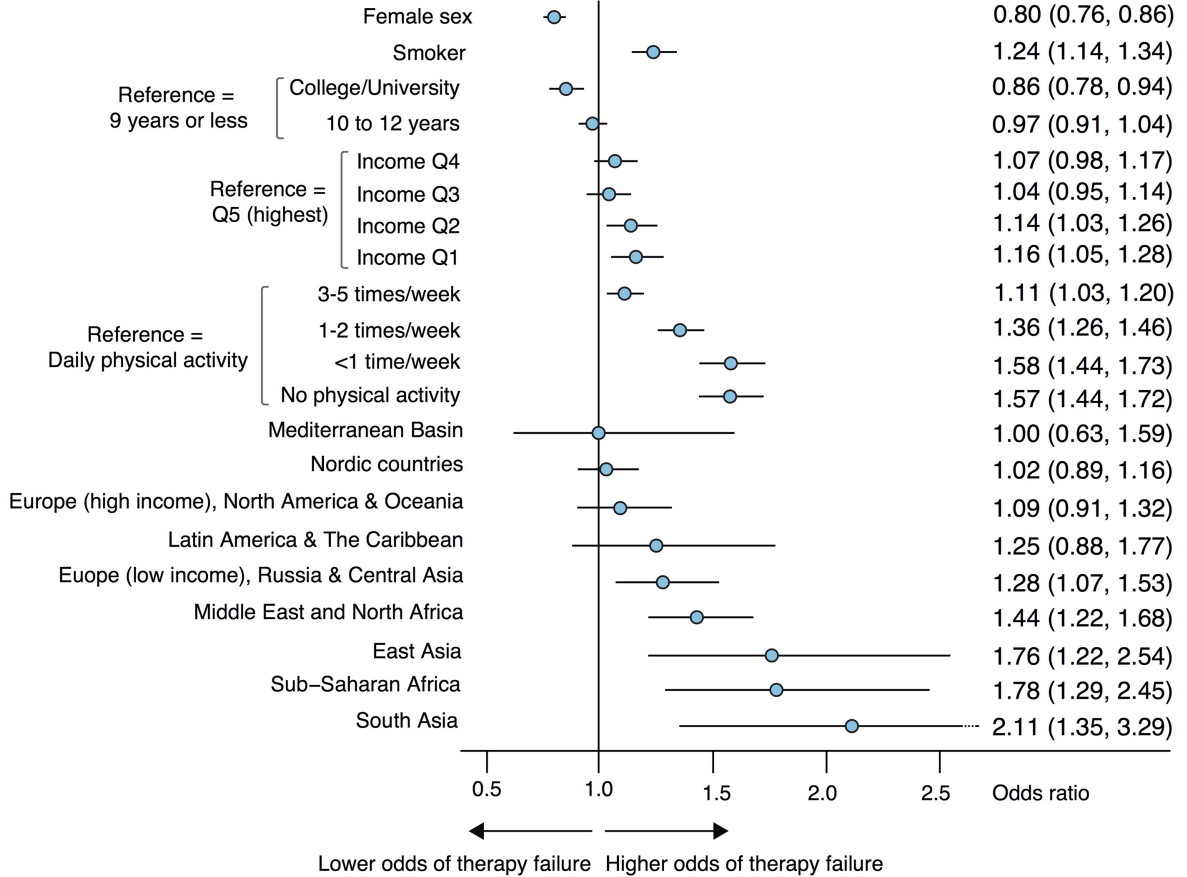

Lower odds of therapy failure Higher odds of therapy failure

Glucose control is a cornerstone of diabetes care. Previous studies on ethnic differences in glycaemic control might be compromised in several ways: unequal access to-or use of-healthcare, inappropriately broad categories of ethnicity, cross-sectional design, small samples and short follow-up, are frequent flaws that might explain contradictory results. ${ }^{6-8}$

We examined 131935 newly diagnosed patients with type 2 diabetes, including 713495 observations during a decade of monitoring. Our cohort contains the majority of all new cases of type 2 diabetes in Sweden during the study period. All major ethnic groups were adequately represented. All participants had full access to every level of healthcare at a minimal cost. The Swedish social welfare system fully covers all necessary healthcare for individuals who do not have an income. Thus, neither access to nor consumption of healthcare is likely to have confounded our results. Swedish authorities frequently target immigrant and disadvantaged groups in ways to increase their use of healthcare and promote health behaviours. This was reflected, in our study, by the fact that immigrants had $30 \%$ more appointments at their clinic.
Figure 3 Probability (OR) of having albuminuria during the second year after diagnosis. Adjusted for age, sex, systolic blood pressure and estimated glomerular filtration rate.

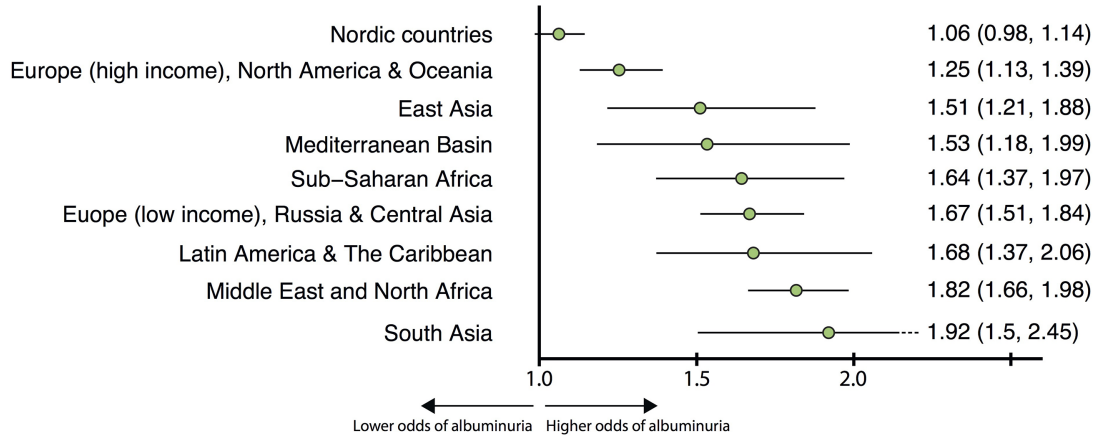


We noted marked ethnic differences in HbA1c both at the time of diagnosis and during follow-up. Immigrants consistently exhibited poorer glycaemic control. High-income Western groups remained below the target-level of HbA1c for 4-5 years after diagnosis, whereas low-income European countries, Russia and Central Asian patients maintained the target level for an average of only 3 years. Non-Western populations had substantially higher HbAlc throughout the study and never reached the guideline target level. Adjusted figures showed 2-5 mmol/mol higher HbAlc among non-Western groups. These disparities translated into a 28-111\% higher risk of not achieving target level of HbA1c and a 51-92\% higher risk of developing albuminuria among non-Western groups compared with native Swedes. After the end of follow-up, $40-45 \%$ of individuals from high-income Western countries were in glycaemic control, compared to 5\%, 25\% and 30\% for Sub-Saharan Africa, South Asia, and the Middle East and North Africa, respectively. These differences could not be explained by disparities in instituting glucoselowering medications use, or access to healthcare.

A recent Scottish study compared glycaemic control in Pakistanis, Indians, Chinese and African-Caribbeans with white Scottish individuals. Unadjusted figures revealed that, compared to the white Scottish group, all other groups had significantly greater proportions of people with suboptimal glycaemic control (defined as HbA1c $>58 \mathrm{mmol} / \mathrm{mol}$ ). Adjusted ORs for suboptimal glycaemic control were significantly higher among Pakistanis (OR 1.85 (95\% CI 1.68 to 2.04)) and Indians (1.62 (95\% CI 1.38 to 1.89$)) .{ }^{9}$ This is in line with our results, and we provide additional details and ethnic groups to this comparison.

The risk of albuminuria was assessed in order to determine whether ethnic differences in glycaemic control were reflected in the development of diabetes-related complications. Poor glycaemic control is a main cause of albuminuria and renal lesions in diabetes, making albuminuria a suitable marker for complications. ${ }^{32} 33$

Studies have shown that African-Americans and Hispanics have a higher prevalence of albuminuria compared with Caucasians. ${ }^{34}$ Jolly et $a l^{35}$ reported that this was also true for Asians. Our study describes the adjusted risk of albuminuria in all major ethnic groups; immigrants, particularly those of non-Western origin, have a substantially higher risk of developing albuminuria. This predicts a high future risk of developing cardiovascular disease. It also suggests that ethnic differences in HbAlc reflect actual differences in glucose-levels. Above all, it underlines the need for ethnic-specific screening and management.

This study shows that South Asians have the greatest risk of developing albuminuria. Previous studies have shown that South Asians exhibit poor risk factor control and have an exceptionally high waist-hip-ratio; ${ }^{36} 37$ they are at greater risk of developing diabetes; ${ }^{38} 39$ they develop diabetes earlier in life; ${ }^{40} 41$ and they exhibit poor glycaemic control. ${ }^{9}{ }^{42}$ A recent study demonstrated that the cut-offs for overweight and obesity in South Asians are substantially lower than cut-offs for white Europeans. ${ }^{43}$ Clinicians should be aware of this vulnerability and intensify risk factor control in South Asians.

The groups with the poorest glycaemic control and greatest risk of albuminuria in our study were Asia, Sub-Saharan Africa, the Middle East and North Africa, low-income Europe, Russia and Central Asia. They represent a large and growing proportion of the population in high-income areas such as North America and the European Union. We believe our results can be generalised to economically developed Western countries. Clinicians and healthcare planners should be aware of the challenges posed by immigrants and adjust the management accordingly. Effective strategies to reduce these health disparities remain elusive and need to be addressed. The problem might be further complicated by a potential interaction between ethnicity and the effectiveness of glucose-lowering medications. Although our study was not designed to explore these associations, we show that there was an effect-modification of ethnicity on glucose-lowering therapy. A previous study revealed ethnic differences in the efficacy of insulin, ${ }^{44}$ but there are considerable gaps in the knowledge that is currently available on this topic.

\section{LIMITATIONS}

It is important to consider the implications of the use of HbA1c when making ethnic comparisons. HbA1c is not a direct measure of glycaemia and might be influenced by factors that are independent of blood glucose levels. Studies have shown that African-Americans average approximately 0.20 percentage points higher HbA1c than Caucasian Americans. ${ }^{45}{ }^{46}$ However, the design of these studies differs from ours. Furthermore, African-Americans descend largely from West Africa. Africans exhibit the greatest genetic diversity of all human populations. ${ }^{47} \mathrm{~A}$ recent study examined two African populations and showed that their HbAlc differed; lower levels were found for the East African population. ${ }^{48}$ The African population in our study descends largely from East Africa. Thus, we believe that our results for Sub-Saharan Africans and the remaining ethnicities should be interpreted as reflecting differences in glycaemic control. This is underscored by the fact that, in our study, Sub-Saharan Africa, as well as the remaining non-Western populations, had considerably higher risk of developing albuminuria, a glycaemia-related complication.

We created ethnic categories by grouping geographically adjacent countries. One could argue that this does not measure ethnicity per se. Regrettably, there is no consensus regarding criteria for defining an ethnic group. Many populations, both within and between countries, share characteristics. Moreover, ethnicity is a changeable concept; neighbouring populations tend to 
adapt to and adopt each other, which blurs differences. Some individuals identify themselves with several ethnicities. ${ }^{49}$ We defined rather large ethnic categories by assessing each countries ethnic composition, economic development, history and religion. ${ }^{50} 51$ This ought to encircle ethnically homogenous populations.

\section{CONCLUSIONS}

Despite earlier start of glucose-lowering therapies, full access to healthcare at a minimal cost and more appointments, immigrants-particularly those of non-Western origin-with type 2 diabetes, have substantially higher HbA1c, greater risk of therapy failure and higher probability of developing albuminuria, than native Swedes. The impact of ethnicity on glycaemic control is greater than the effect of income and educational level, and on a par with the effect of physical activity. Thus, ethnicity is integral to glycaemic control and needs to be carefully considered if diabetes care is to improve.

\section{Author affiliations}

${ }^{1}$ Department of Molecular and Clinical Medicine, University of Gothenburg, Gothenburg, Sweden

${ }^{2}$ Sahlgrenska University Hospital, Gothenburg, Sweden

${ }^{3}$ National Diabetes Register, Centre of Registers, Gothenburg, Sweden

${ }^{4}$ Department of Public Health and Caring Sciences/Geriatrics, Uppsala

University, Uppsala, Sweden

${ }^{5}$ Medical Products Agency, Epidemiology, Uppsala, Sweden

Acknowledgements The authors would like to thank the various regional NDR coordinators, as well as contributing nurses, physicians and patients. The Swedish Diabetes Association and the Swedish Society of Diabetology support the NDR. The authors would also like to thank George Lappas (University of Gothenburg) and Szilard Nemes (University of Gothenburg) for their valuable statistical guidance.

Contributors ARa, A-MS, ARo, BZ, BE and SG contributed to the conception and design of the study. ARa performed statistical analyses and wrote the first draft of the article. ARa, A-MS, ARo, BZ, BE and SG contributed to the interpretation of data. ARa, A-MS, ARo, BZ, BE and SG contributed to critical revision of the article for important intellectual content.

Funding This study was funded by the Swedish National Diabetes Register. The Swedish Association of Local Authorities and Regions funds the NDR. Additional support: the Swedish Heart and Lung Foundation, and the Swedish Research Council (SIMSAM) (grant numbers 2013-5187 and 2013-4236).

Competing interests None declared.

Ethics approval The regional ethical review board at the University of Gothenburg, Gothenburg, Sweden.

Provenance and peer review Not commissioned; externally peer reviewed.

Data sharing statement The Swedish Data Protection Authority regulates access to the NDR, and any other public database, through the Personal Data Act. Access to data requires approval from The Regional Ethical Review Board, the National Board of Health and Welfare, Statistics Sweden and the Swedish National Diabetes Register. The authors are happy to provide detailed information regarding this.

Open Access This is an Open Access article distributed in accordance with the Creative Commons Attribution Non Commercial (CC BY-NC 4.0) license, which permits others to distribute, remix, adapt, build upon this work noncommercially, and license their derivative works on different terms, provided the original work is properly cited and the use is non-commercial. See: http:// creativecommons.org/licenses/by-nc/4.0/

\section{REFERENCES}

1. Holman RR, Paul SK, Bethel MA, et al. 10-year follow-up of intensive glucose control in type 2 diabetes. $N$ Engl J Med 2008;359:1577-89.

2. Patel A, MacMahon S, Chalmers J, et al, ADVANCE Collaborative Group. Intensive blood glucose control and vascular outcomes in patients with type 2 diabetes. N Engl J Med 2008;358:2560-72.

3. Sarwar N, Gao P, Seshasai SR, et al, Emerging Risk Factors C. Diabetes mellitus, fasting blood glucose concentration, and risk of vascular disease: a collaborative meta-analysis of 102 prospective studies. Lancet 2010;375:2215-22.

4. Seshasai SR, Kaptoge S, Thompson A, et al, Emerging Risk Factors C. Diabetes mellitus, fasting glucose, and risk of cause-specific death. N Engl J Med 2011;364:829-41.

5. Lind M, Bounias I, Olsson M, et al. Glycaemic control and incidence of heart failure in 20,985 patients with type 1 diabetes: an observational study. Lancet 2011;378:140-6.

6. Fan T, Koro CE, Fedder DO, et al. Ethnic disparities and trends in glycemic control among adults with type 2 diabetes in the U.S. from 1988 to 2002. Diabetes Care 2006;29:1924-5.

7. Harris MI, Eastman RC, Cowie CC, et al. Racial and ethnic differences in glycemic control of adults with type 2 diabetes. Diabetes Care 1999;22:403-8.

8. Davis TM, Cull CA, Holman RR, et al. Relationship between ethnicity and glycemic control, lipid profiles, and blood pressure during the first 9 years of type 2 diabetes: U.K. Prospective Diabetes Study (UKPDS 55). Diabetes Care 2001;24:1167-74.

9. Negandhi PH, Ghouri N, Colhoun HM, et al. Ethnic differences in glycaemic control in people with type 2 diabetes mellitus living in Scotland. PLOS ONE 2013;8:e83292.

10. Information UDOP. International migration and development. United Nations Press Release 2013.

11. Ramachandran A, Ma RCW, Snehalatha C. Diabetes in Asia. Lancet 2010;375:408-18.

12. Shai I, Jiang R, Manson JE, et al. Ethnicity, obesity, and risk of type 2 diabetes in women: a 20 -year follow-up study. Diabetes Care 2006;29:1585-90.

13. Richard Sicree JSPZ. The global burden of diabetes and impaired glucose tolerance. International Diabetes Federation, 2013.

14. Lutsey PL, Pereira MA, Bertoni AG, et al. Interactions between race/ ethnicity and anthropometry in risk of incident diabetes: the multiethnic study of atherosclerosis. Am J Epidemiol 2010;172:197-204.

15. Narayan KM, Boyle JP, Thompson TJ, et al. Lifetime risk for diabetes mellitus in the United States. JAMA 2003;290:1884-90.

16. Davis K, Ballreich J. Equitable access to care-how the United States ranks internationally. N Engl J Med 2014;371:1567-70.

17. Billing A. Health assessment of newly immigrated individuals. http://www.folkhalsomyndigheten.se/pagefiles/12920/ halsoundersokningar-nyanlanda-invandrare.pdf

18. Haglind $\mathrm{P}$, ed. Tobacco prevention among immigrants. 2nd edn Institute of Population Health, 2012. http://www.folkhalsomyndigheten. se/documents/livsvillkor-levnadsvanor/andts/tobak/uppdrag/ nationella-tobaksuppdraget/samverkansprojektet/slutrapporttobaksprevention-invandrargrupper.pdf

19. Lind M, Svensson A-M, Kosiborod M, et al. Glycemic control and excess mortality in type 1 diabetes. $N$ Engl J Med 2014;371: 1972-82.

20. Gudbjornsdottir S, Cederholm J, Nilsson PM, et al. The National Diabetes Register in Sweden: an implementation of the St. Vincent Declaration for Quality Improvement in Diabetes Care. Diabetes Care 2003;26:1270-6.

21. Ekström N, Schiöler L, Svensson A-M, et al. Effectiveness and safety of metformin in 51675 patients with type 2 diabetes and different levels of renal function: a cohort study from the Swedish National Diabetes Register. BMJ Open 2012;2:e001076-6.

22. Cederholm J, Gudbjörnsdottir S, Eliasson B, et al. Blood pressure and risk of cardiovascular diseases in type 2 diabetes: further findings from the Swedish National Diabetes Register (NDR-BP II). J Hypertens 2012;30:2020-30.

23. Lind $\mathrm{M}$, Olsson $\mathrm{M}$, Rosengren $\mathrm{A}$, et al. The relationship between glycaemic control and heart failure in 83,021 patients with type 2 diabetes. Diabetologia 2012;55:2946-53.

24. Rotimi CN, Jorde LB. Ancestry and disease in the age of genomic medicine. N Engl J Med 2010;363:1551-8.

25. Hoelzel W, Weykamp C, Jeppsson J-O, et al. IFCC reference system for measurement of hemoglobin A1c in human blood and the national standardization schemes in the United States, Japan, and Sweden: a method-comparison study. Clin Chem 2004;50:166-74.

26. Levey AS, Bosch JP, Lewis JB, et al. A more accurate method to estimate glomerular filtration rate from serum creatinine: a new 
prediction equation. Modification of Diet in Renal Disease Study Group. Ann Intern Med 1999;130:461-70.

27. Ludvigsson JF, Andersson E, Ekbom A, et al. External review and validation of the Swedish national inpatient register. BMC Public Health 2011;11:450.

28. Ingelsson E, Arnlöv J, Sundström J, et al. The validity of a diagnosis of heart failure in a hospital discharge register. Eur $\mathrm{J}$ Heart Fail 2005;7:787-91.

29. Diggle PJ HPLK-YZS. Analysis of longitudinal data. 2nd edn. Oxford University Press, 2002.

30. Egede LE, Gebregziabher M, Hunt KJ, et al. Regional, geographic, and racial/ethnic variation in glycemic control in a national sample of veterans with diabetes. Diabetes Care 2011;34:938-43.

31. Weinstock RS, Teresi JA, Goland R, et al. Glycemic control and health disparities in older ethnically diverse underserved adults with diabetes: five-year results from the Informatics for Diabetes Education and Telemedicine (IDEATel) study. Diabetes Care 2011;34:274-9.

32. Mogensen CE, Poulsen PL. Microalbuminuria, glycemic control, and blood pressure predicting outcome in diabetes type 1 and type 2 . Kidney Int Suppl 2004;66:S40-1.

33. Levin SR, Coburn JW, Abraira C, et al. Effect of intensive glycemic control on microalbuminuria in type 2 diabetes. Veterans Affairs Cooperative Study on Glycemic Control and Complications in Type 2 Diabetes Feasibility Trial Investigators. Diabetes Care 2000;23:1478-85

34. Sinha SK, Shaheen M, Rajavashisth TB, et al. Association of race/ ethnicity, inflammation, and albuminuria in patients with diabetes and early chronic kidney disease. Diabetes Care 2014;37:1060-8.

35. Jolly SE, Burrows NR, Chen S-C, et al. Racial and ethnic differences in albuminuria in individuals with estimated GFR greater than $60 \mathrm{~mL} /$ $\mathrm{min} / 1.73 \mathrm{~m}(2)$ : results from the Kidney Early Evaluation Program (KEEP). Am J Kidney Dis 2010;55:S15-22.

36. Lean ME, Han TS, Bush $\mathrm{H}$, et al. Ethnic differences in anthropometric and lifestyle measures related to coronary heart disease risk between South Asian, Italian and general-population British women living in the west of Scotland. Int $J$ Obes Relat Metab Disord 2001;25:1800-5.

37. Forouhi NG, Sattar N, Tillin T, et al. Do known risk factors explain the higher coronary heart disease mortality in South Asian compared with European men? Prospective follow-up of the Southal and Brent studies, UK. Diabetologia 2006;49:2580-8.

38. Danaei G, Finucane MM, Lu Y, et al. National, regional, and global trends in fasting plasma glucose and diabetes prevalence since 1980: systematic analysis of health examination surveys and epidemiological studies with 370 country-years and 2.7 million participants. Lancet 2011;378:31-40.

39. Bellary S, O'Hare JP, Raymond NT, et al. Premature cardiovascular events and mortality in south Asians with type 2 diabetes in the United Kingdom Asian Diabetes Study-effect of ethnicity on risk. Curr Med Res Opin 2010;26:1873-9.

40. Mukhopadhyay B, Forouhi NG, Fisher BM, et al. A comparison of glycaemic and metabolic control over time among South Asian and European patients with type 2 diabetes: results from follow-up in a routine diabetes clinic. Diabet Med 2006;23:94-8.

41. Ethnicity and cardiovascular disease. The incidence of myocardial infarction in white, South Asian, and Afro-Caribbean patients with type 2 diabetes (U.K. Prospective Diabetes Study 32). Diabetes Care 1998;21:1271-7.

42. Fischbacher CM, Bhopal R, Steiner M, et al. Is there equity of service delivery and intermediate outcomes in South Asians with type 2 diabetes? Analysis of DARTS database and summary of UK publications. J Public Health (Oxf) 2009;31:239-49.

43. Ntuk UE, Gill JMR, Mackay DF, et al. Ethnic-specific obesity cutoffs for diabetes risk: cross-sectional study of 490,288 UK biobank participants. Diabetes Care 2014:37:2500-7.

44. Davidson JA, Wolffenbuttel BH, Arakaki RF, et al. Impact of race/ ethnicity on efficacy and safety of two starter insulin regimens in patients with type 2 diabetes: a posthoc analysis of the DURABLE trial. Ethn Dis 2013;23:393-400.

45. Ziemer DC, Kolm P, Weintraub WS, et al. Glucose-independent, black-white differences in hemoglobin A1c levels: a cross-sectional analysis of 2 studies. Ann Intern Med 2010;152:770-7.

46. Herman $\mathrm{WH}, \mathrm{Ma} \mathrm{Y}$, Uwaifo $\mathrm{G}$, et al. Differences in $\mathrm{A} 1 \mathrm{C}$ by race and ethnicity among patients with impaired glucose tolerance in the Diabetes Prevention Program. Diabetes Care 2007;30:2453-7.

47. Tishkoff SA, Reed FA, Friedlaender FR, et al. The genetic structure and history of Africans and African Americans. Science 2009;324:1035-44.

48. Hare MJL, Magliano DJ, Zimmet PZ, et al. Glucose-independent ethnic differences in $\mathrm{HbA} 1 \mathrm{c}$ in people without known diabetes. Diabetes Care 2013;36:1534-40.

49. Braun L, Fausto-Sterling A, Fullwiley D, et al. Racial categories in medical practice: how useful are they? PLoS Med 2007;4:e271.

50. The Central Intelligence Agency. The World Fact Book. https://www. cia.gov/library/publications/the-world-factbook/ (accessed 7 Mar 2015).

51. Bank TW. Classification of Countries. http://www.worldbank.org/en/ country (accessed 7 Mar 2015). 